\title{
Dual-Platform Proteomics Study of Plasma Biomarkers in Pediatric Patients Undergoing Cardiopulmonary Bypass
}

\author{
TODD M. UMSTEAD, CHIA-JUNG K. LU, WILLARD M. FREEMAN, JOHN L. MYERS, J. BRIAN CLARK, NEAL J. THOMAS, \\ VERNON M. CHINCHILLI, KENT E. VRANA, AKIF ÜNDAR, AND DAVID S. PHELPS
}

\author{
Department of Pediatrics [T.M.U., C.-J.K.L., J.L.M., J.B.C., N.J.T., A.Ü., D.S.P.], Department of Pharmacology [W.M.F., K.E.V.], \\ Department of Surgery [J.L.M., J.B.C., A.Ü.], Department of Public Health Sciences [N.J.T., V.M.C.], Department of Bioengineering \\ [A.Ü.], Pennsylvania State University College of Medicine, Hershey, Pennsylvania 17033
}

\begin{abstract}
Plasma samples from pediatric cardiac patients undergoing cardiopulmonary bypass (CPB) procedures were used to identify and characterize patterns of changes in potential biomarkers related to tissue damage and inflammation. These included proteins associated with systemic inflammatory response syndrome. Potential biomarkers were identified using a dual-platform proteomics approach requiring $\sim 150 \mu \mathrm{L}$ of plasma, which included twodimensional difference gel electrophoresis (2D-DIGE) and a multiplexed immunoassay. Methods used in the dual approach measured levels of 129 proteins in plasma from pediatric CPB patients. Of these, 70 proteins changed significantly $(p<0.05)$ between time points, and 36 of these retained significance after the highly stringent Bonferroni correction [ $p<0.001$ for 2D-DIGE and $p<0.00056$ for multianalyte profile (MAP) assays]. Many of the changing proteins were associated with tissue damage, inflammation, and oxidative stress. This study uses a novel approach that combines two discovery proteomics techniques to identify a pattern of potential biomarkers changing after $\mathrm{CPB}$. This approach required only $150 \mu \mathrm{L}$ of plasma per time point and provided quantitative information on 129 proteins. The changes in levels of expression of these proteins may provide insight into the understanding, treatment, and prevention of systemic inflammation, thereby helping to improve the outcomes of pediatric CPB patients. (Pediatr Res 67: 641-649, 2010)
\end{abstract}

$\mathrm{C}$ onsiderable evidence suggests that systemic inflammation is responsible for many postoperative complications that can lead to multiple organ dysfunction syndrome (1). Currently, there are no effective methods for preventing systemic inflammatory response syndrome (SIRS) in cardiac surgery patients (1). We hypothesize that identifying a panel of biomarkers related to systemic inflammation associated with cardiopulmonary bypass $(\mathrm{CPB})$ could prove useful in predicting patient outcome, identifying potential targets for treatment, and reducing the incidence of vital organ dysfunction and other complications.

Received September 8, 2009; accepted January 17, 2010.

Correspondence: Akif Ündar, Ph.D., Departments of Pediatrics, Surgery and Bioengineering, Penn State Hershey College of Medicine, 500 University Drive, Hershey, PA 17033; e-mail: aundar@psu.edu

Supported by the Children's Miracle Network (to A.Ü.) and by a grant from the Barsumian Foundation (to W.M.F.).

A.Ü. and D.S.P. contributed equally to this work.

Supplemental digital content is available for this article. Direct URL citations appear in the printed text and are provided in the HTML and PDF versions of this article on the journal's Web site (www.pedresearch.org).
We have established a multidisciplinary research team for combining clinical, basic science, and engineering tools focused on minimizing vital organ injury during CPB procedures in neonates, infants, and small children (2-5). In previous pilot reports, we have used two-dimensional difference gel electrophoresis (2D-DIGE), a gel-based discovery proteomics approach to study changes in plasma protein expression in pediatric patients undergoing CPB $(2,3)$. In these studies, we have identified some proteins whose levels are consistently altered by CPB.

In the current study, we used a dual-platform proteomics approach to compare plasma protein samples before and after cardiac surgery involving CPB to identify potential plasma biomarkers, particularly those related to SIRS, and to characterize the changes they undergo during CPB. One platform used was 2D-DIGE, a gel-based discovery proteomics technique $(6,7)$, coupled with matrix-assisted laser desorption ionization-time-of-flight/time-of-flight (MALDI-ToF/ToF) tandem mass spectrometry. This combination of methods for protein quantification and identification of proteins has proven very useful in doing quantitative comparisons of protein, and our group has used it in several preliminary investigations of plasma protein changes after CPB $(2,3)$. We coupled our 2D-DIGE studies with a commercially available multianalyte immunoassay capable of measuring 90 different proteins, including many low abundance molecules and some proteins that were also identified and quantified by 2D-DIGE. The pairing of these techniques made it possible to simultaneously analyze changes in expression of 129 proteins in plasma, potentially allowing us to identify proteins and pathways, which have not been explored in previous studies of CPB.

\section{MATERIALS AND METHODS}

Cardiopulmonary bypass. Isoflurane and fentanyl facilitated with pancuronium was used to maintain anesthesia, and a median sternotomy was used for all operations. The CPB circuit used a Jostra HL-20 heart-lung machine (Jostra USA, Austin, TX), a Stockert heart-cooler system (Sorin Group USA, Arvada, CO), Capiox hollow fiber membrane oxygenators, and a Capiox

\footnotetext{
Abbreviations: CPB, cardiopulmonary bypass; MALDI-ToF/ToF, matrixassisted laser desorption ionization-time-of-flight/time-of-flight; MAP, multianalyte profile; MS/MS, mass spectrometry and tandem mass spectrometry; SIRS, systemic inflammatory response syndrome; 2D-DIGE, two-dimensional difference gel electrophoresis
} 
pediatric $32 \mu \mathrm{m}$ arterial filter (Terumo Cardiovascular Systems, Ann Arbor, MI). Conventional nonpulsatile flow was used in all patients. Circuit priming solution comprising lactated Ringer's, albumin, and blood was provided. Jenkins (8) risk categories [RACHS-1 (risk adjustment for congenital heart surgery)] were used for analyzing severity of surgical procedures. Cardioplegia is administered through a cannula inserted into the ascending aorta placed between the heart and the aortic cross-clamp. The composition of the solution is four parts oxygenated blood to one part Buckberg cardioplegic solution (cold induction formula) administered at $6-8^{\circ} \mathrm{C}$ for $4 \mathrm{~min}$ to arrest the heart. The flow is adjusted to deliver the cardioplegia at a system pressure of 90-100 mm Hg. Subsequent maintenance doses using the "multidose formula" are administered every $20-30 \mathrm{~min}$ for $2 \mathrm{~min}$. Characteristics of the patients and CPB parameters and clinical data are tabulated in Table 1.

Sample collection and storage. This study was approved by the Penn State College of Medicine Institutional Review Board, and consent forms were signed for all enrolled patients. In addition, a Data Safety Monitoring Board has been established for this study. Blood samples were collected in tubes containing potassium EDTA from 10 pediatric patients undergoing CPB. A baseline sample was collected for each patient $\sim 30 \mathrm{~min}$ before incision and another sample $24 \mathrm{~h}$ after weaning from CPB. The blood was centrifuged, the plasma was removed, and the aliquots were stored at $-80^{\circ} \mathrm{C}$ until analysis.

Depletion of plasma for 2D-DIGE. Removal of 14 high abundance serum proteins (albumin, IgG, $\alpha$-1-antitrypsin, IgA, transferrin, haptoglobin, fibrinogen, $\alpha$-2-macroglobulin, $\alpha$-1-acid glycoprotein, IgM, apolipoprotein A-I, apolipoprotein A-II, complement C3, and transthyretin) was performed using a Human 14 Multiple Affinity Removal System (MARS) column, $4.6 \times 100$ $\mathrm{mm}$ (Agilent Technologies, Inc., Palo Alto, CA) following the manufacturer's instructions. Briefly, $40 \mu \mathrm{L}$ of plasma was diluted to a final volume of $500 \mu \mathrm{L}$ with buffer A (Agilent Technologies) and filtered through a $0.22-\mu \mathrm{m}$ filter before applying to the column. The proteins that did not bind were subjected to 2D-DIGE. Plasma depletion was performed only on samples to be analyzed by 2 D-DIGE, and no depletion was done on those to be analyzed by the multianalyte immunoassay.

Sample preparation for $2 D-D I G E$. Preparation of samples and 2D-DIGE procedures were described previously (7). Additional information about the 2D-DIGE study is provided in a form that is in concordance with the minimum information about a proteomics experiment (MIAPE)-gel electrophoresis standards (9), which are currently under development by the Human Proteome Organization Proteomics Standards Initiative (HUPO-PSI) (Table S1: http://links.lww.com/PDR/A59). Depleted samples $(50 \mu \mathrm{g})$ were subjected to minimal labeling with CyDye DIGE Fluors for 2D-DIGE following the manufacturer's instructions (GE Healthcare). Individual samples were randomly labeled with either $\mathrm{Cy} 3$ or $\mathrm{Cy} 5$ in equal numbers, and a normalization pool containing an equal amount of each sample was created and labeled with Cy2. A second pool containing equal amounts of each sample was also created and left unlabeled to be used for the preparative/picking gel for identification of protein spots by mass spectrometry.

Two-dimensional difference gel electrophoresis. For 2D-DIGE, $50 \mu \mathrm{g}$ of a Cy3-labeled sample, $50 \mu \mathrm{g}$ of a Cy5-labeled sample, and $50 \mu \mathrm{g}$ of the Cy2-labeled pool were mixed for each gel. Samples were applied to prehydrated 24-cm pH 4-7 Immobiline DryStrips (GE Healthcare) using cup loading and subjected to isoelectric focusing. After focusing, strips were equilibrated and sealed on second-dimension $10 \%$ polyacrylamide gels (20.5 $\mathrm{cm}-\mathrm{L} \times 25.5 \mathrm{~cm}-\mathrm{W} \times 1 \mathrm{~mm}-\mathrm{D})$ using agarose and the focused proteins separated by molecular weight. Gels were then imaged with a Typhoon 9400 fluorescent imager (GE Healthcare) using a different emission filter for each CyDye, and the images were analyzed using Progenesis SameSpots (version 2.0; Nonlinear USA, Durham, NC). Preparative/picking gels were stained using Deep Purple Total Protein Stain (GE Healthcare) and then, also, imaged using the Typhoon 9400 .

Protein identification by mass spectrometry. Identification of proteins by mass spectrometry was performed as described previously (7). Briefly, protein spots were picked from preparative/picking gels using the Ettan Spot Picker (GE Healthcare) and the gel plugs digested with trypsin. The digested proteins/peptides were extracted from the gel plugs, cleaned and concentrated using $\mathrm{C}_{18}$ ZipTips (Millipore, Billerica, MA), and spotted onto 384-well MALDI plates with matrix. Peptides were analyzed by mass spectrometry using the 4800 MALDI ToF/ToF Proteomics Analyzer (Applied Biosystems) in the Mass Spectrometry Core at the Penn State College of Medicine. GPS Explorer 3.6 software (Applied Biosystems) was used to submit the mass spectrometry (MS) and tandem mass spectrometry (MS/MS) data to the MASCOT search engine and the NCBI nonredundant database, and human taxonomy was used for identification. MASCOT confidence interval scores of $>95 \%$ were considered a positive protein identification. For proteins having multiple isoforms, statistical analyses were done on the sum of all identified isoforms for that protein.
Multianalyte profile assays. An undepleted $100 \mu \mathrm{L}$ aliquot of each sample was sent to Rules Based Medicine (Austin, TX), a clinical laboratory improvement amendments (CLIA)-certified laboratory. Analysis of the samples was performed using the HumanMAP version 1.6 Antigen panel, capable of detecting 90 different human antigens related to tissue damage, inflammation, or other pathologies.

Statistical and bioinformatic analysis. Information about the acquisition and processing of data from the 2D-DIGE studies are provided in the form recommended for MIAPE Gel Informatics currently being developed by the HUPO-PSI (http://www.psidev.info/index.php?q = node/83) (Table S2: http://links.lww.com/PDR/A59). Multivariate statistical analysis of the proteomic data for the protein spots was done using Progenesis Stats (Nonlinear USA) to perform principal components analysis (PCA), power analysis of the data, and for $t$ tests for the individual spots. Protein measurements from both the 2D-DIGE and multianalyte profile (MAP) methods were analyzed separately, and their values were transformed to natural logarithms to better approximate normality. A repeated measurements analysis of variance was applied to compare samples collected at the two time points using SAS version 9.1 (SAS Institute, Cary, NC). Significance was reported both with and without Bonferroni adjustments.

Proteins identified as having significant changes $(p<0.05$ by repeated measurements) either by 2D-DIGE or MAP were then combined for bioinformatic analyses. Ontological groupings were analyzed for these proteins using the PANTHER database (www.pantherdb.org) (SRI International) (10). All proteins undergoing significant changes were then imported into the Ingenuity Pathway Analysis (IPA) system (Ingenuity Systems, Redwood City, CA) to visualize and examine potential networks of proteins and canonical pathways.

\section{RESULTS}

2D-DIGE analysis. Passage of plasma samples through the Human-14 MARS column removed $\sim 95 \%$ of the original protein content containing the 14 most abundant plasma proteins. The completeness of removal of these proteins was confirmed by the absence of spots corresponding to them on the resulting 2D-DIGE gels.

A total of 556 protein spots were visualized and matched in all gels. Of the 556 matched spots, 175 (31.5\%) changed significantly from the baseline (pre-CPB) time point to the $24 \mathrm{~h}$ post-CPB time point $(t$ test, $p<0.05)$ with $75(13.5 \%)$ increases and $100(18.0 \%)$ decreases. By using MALDI-ToF/ToF, we identified (with MASCOT confidence interval scores of $>95 \%$ ) the proteins that comprised 269 of the 556 matched spots. The identified spots accounted for $48.4 \%$ of the total spots and $88.0 \%$ of the total expressed protein resolved by the gel.

Many plasma proteins consist of a number of isoforms corresponding to multiple gel spots. Therefore, after analysis and identification of individual gel spots, we added together the normalized volumes for all gel spots/isoforms that were determined by MALDI-ToF/ToF to be isoforms of the same protein and performed statistical analysis on the new values representing the whole proteins. A list of proteins, including NCBI and Swiss-Prot accession numbers and the biologic processes and molecular functions assigned to each by the PANTHER database for all identified 2D-DIGE proteins, can be found in the Table S3 (http://links.lww.com/PDR/A59).

Figure 1 depicts the reference gel with the identified proteins and all of their isoforms circled and numbered. Fortyfour proteins were identified by 2D-DIGE and MALDI-ToF/ ToF. These were compared, and it was determined that 25 (56.8\%) changed significantly $(p<0.05$ by repeated measurements analysis) between time points with $10(22.7 \%)$ protein increases and $15(34.1 \%)$ protein decreases. These proteins are listed in Table 2. We then reevaluated these changes after 


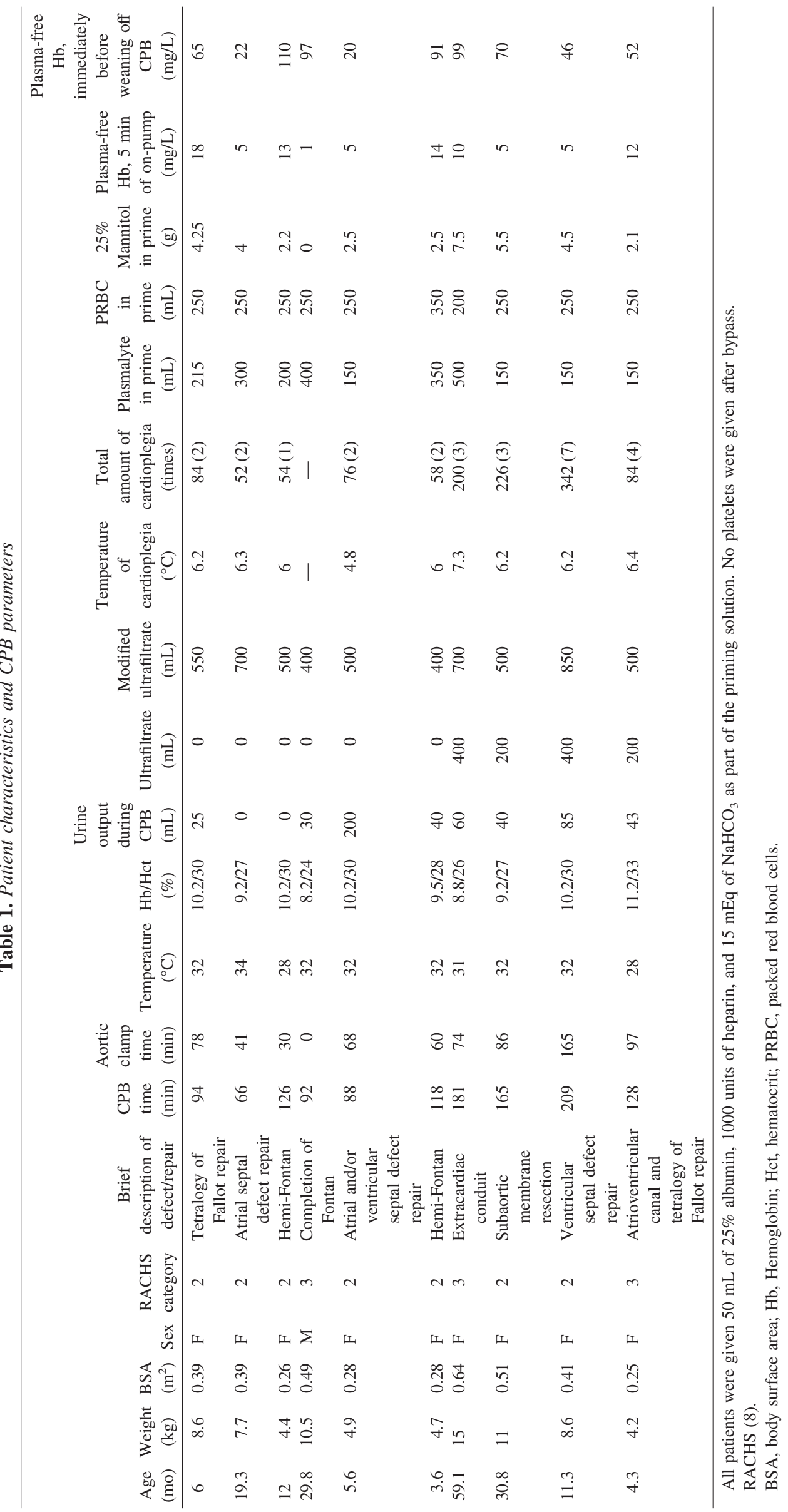




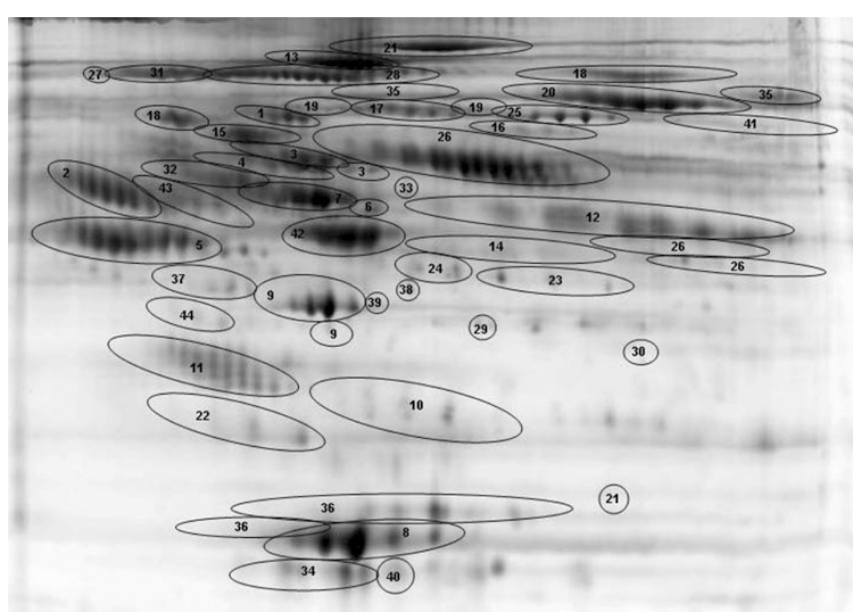

Figure 1. Reference gel image of depleted plasma proteins identified by 2D-DIGE. All identified proteins are circled and numbered. Note that all gel spots within each circle were independently identified. 1, Afamin; 2, alpha1-antichymotrypsin; 3, alpha-1-B-glycoprotein; 4, alpha-2-antiplasmin; 5, alpha2-HS glycoprotein (fetuin-A); 6, angiotensinogen; 7, antithrombin (antithrombin III); 8, apolipoprotein A-I ${ }^{\mathrm{M}}$; 9, apolipoprotein A-IV; 10, apolipoprotein $\mathrm{E} ; 11$, apolipoprotein $\mathrm{J}$ (clusterin); 12, apolipoprotein-H (beta-2glycoprotein-I) $^{\mathrm{M}}$; 13, ceruloplasmin; 14, CFI protein (complement factor I); 15, coagulation factor II (thrombin); 16, coagulation factor XIIIb; 17, complement component $1 ; 18$, complement component $6 ; 19$, complement component $\mathrm{C} 4 ; 20$, complement factor $\mathrm{B} ; 21$, complement factor $\mathrm{H} ; 22$, complex-forming glycoprotein HC (AMBP); 23, EPC-1 (PEDF) (pigment epithelium-derived factor); 24, Fibrinogen gamma chain ${ }^{\mathrm{M}}$; 25, gelsolin; 26, hemopexin; 27, inter-alpha (globulin) inhibitor $\mathrm{H} 2 ; 28$, inter-alpha-trypsin inhibitor $\mathrm{H} 4 ; 29$, keratin 9; 30, keratin 10; 31, kininogen 1 isoform $1 ; 32$, kininogen 1 isoform 2; 33, LBP precursor; 34, plasma retinol-binding protein (retinol-binding protein 4); 35, plasminogen (angiostatin); 36, serum amyloid P component ${ }^{\mathrm{M}}$; 37, serum paraoxonase; 38, SHBG (sex hormone-binding globulin) ${ }^{\mathrm{M}} ; 39$, solute carrier family 25 , member $42 ; 40$, tetranectin (TN); 41, transferrin (serotransferrin); 42, vitamin D binding protein (group-specific component); 43, vitronectin; 44, zinc-alpha-2-glycoprotein. Proteins that were also identified by MAP analysis (M).

applying the Bonferroni correction for multiple comparisons, and the number of significant proteins $(p<0.001)$ was reduced to $17(38.6 \%)$ with $8(18.2 \%)$ increases and $9(20.4 \%)$ decreases. These proteins are listed in the upper part of Table 2 and designated by "*." A complete listing of all proteins identified by 2D-DIGE, their values, and percent change can be found in Table S3 (http://links.lww.com/PDR/A59).

MAP analysis. MAP analysis was performed by Rules Based Medicine using the HumanMAP version 1.6 Antigen panel, which detected a total of 90 proteins. A list of proteins, including NCBI and Swiss-Prot accession numbers, and PANTHER assignments for all proteins measured by the MAP assay, can be found in Table S4 (http://links.lww.com/PDR/A59). As with the 2D-DIGE study, we first compared the time points by repeated measurements. Of these 90 proteins, $49(54.4 \%)$ were shown to change significantly ( $p<0.05$ by repeated measurements) between the time points with $26(28.9 \%)$ increases and $23(25.5 \%)$ decreases. These proteins are listed in Table 3. We then applied the Bonferroni adjustment, and the number of significant changes $(p<0.00056)$ was reduced to $21(23.3 \%)$ with $16(17.8 \%)$ increases and $5(5.5 \%)$ decreases. These proteins are listed in the upper part of Table 3 and designated by "*." A complete listing of all proteins quantified by the
MAP assay, their values, and percent change can be found in Table S4 (http://links.lww.com/PDR/A59).

Combined analysis of $2 D-D I G E$ and MAP proteins. Of the 129 proteins identified and quantified in this study, five were quantified by both methods, and the percent change for proteins detected by both platforms was similar, although not identical (Tables S3 and S4: http://links.lww.com/PDR/A59). Proteins undergoing significant changes between time points with $\geq 50 \%$ change are shown in Figure 2 .

We used the PANTHER database to gain insight into the functional implications of the changes in protein expression after CPB. For this analysis, only proteins with significant changes were entered into PANTHER to determine their potential impact on molecular functions and biologic processes. These are depicted in Figure 3 with proteins separated into those that increased (Fig. $3 A$ and $C$ ) and those that decreased (Fig. $3 B$ and $D$ ). Note that PANTHER may attribute many functions and/or processes to a given protein. Many of the proteins with significant changes in expression are categorized by the molecular function of "signaling molecule (SIGN)," "select regulatory molecule (SRM)," and "defense/ immunity protein (DIP);" with biologic processes of "signal transduction (ST)," "protein metabolism and modification (PMM)," and "immunity and defense (ID)," respectively. The molecular functions (Fig. $3 A$ and $B$ ) and biologic processes (Fig $3 C$ and $D$ ) attributed to the proteins by the PANTHER database are shown in pie charts for all plasma proteins with significant changes in expression between time points. The data in Tables 2 and 3 and Table S3 and S4 (http://links.lww.com/PDR/A59) reveal that most of the proteins with the greatest changes in expression $(>200 \%)$ are included in the above-mentioned PANTHER categories, indicating that these categories are not only the ones with the most significant protein changes but that they also contain the proteins with the largest changes in expression.

We then performed an Ingenuity Pathways analysis on the combined list of all significantly changing proteins identified by 2D-DIGE and MAPs. This analysis demonstrated that the canonical "acute phase response signaling" pathway was the most highly regulated $(p<6.75 \mathrm{E}-27)$ of the pathways incorporating these set of proteins (Fig. 4). Patterns of expression for the identified proteins closely match those predicted by the acute phase response pathway and suggest that interleukin (IL)-6 may be an important mediator in the up-regulation of many of the proteins, possibly acting through the JAK2/ STAT3 pathway.

\section{DISCUSSION}

Because of the potentially serious sequelae that SIRS can cause, there have been many studies attempting to identify biomarkers that could be used to predict, diagnose, and monitor its clinical course. SIRS may occur in a wide variety of conditions, so defining subgroups could enhance the development of treatment options $(11,12)$. A number of biomarkers for SIRS have been used in the past including, but not limited to, IL-6, procalcitonin, and C-reactive protein (CRP) (13-15). These three proteins showed the greatest changes in the 
Table 2. 2D-DIGE proteins with significant changes

\begin{tabular}{|c|c|c|c|c|}
\hline Gel no. & Protein ID & Percent change & Baseline & $24 \mathrm{hr}$ Post-CPB \\
\hline 2 & Alpha-1-antichymotrypsin* & 110.5 & $4.45(0.777)$ & $9.36(0.892)$ \\
\hline 5 & Alpha2-HS glycoprotein (fetuin-A)* & -24.5 & $11.05(2.405)$ & $8.88(1.909)$ \\
\hline 6 & Angiotensinogen* & 29.7 & $2.65(0.445)$ & $3.44(0.553)$ \\
\hline 14 & CFI protein* & -17.0 & $6.69(1.408)$ & $5.72(0.863)$ \\
\hline 15 & Coagulation factor II (thrombin)* & -10.3 & $1.06(0.071)$ & $0.96(0.051)$ \\
\hline 16 & Coagulation factor XIIIb* & -23.5 & $4.26(0.491)$ & $3.45(0.418)$ \\
\hline 18 & Complement component $6^{*}$ & 10.1 & $0.92(0.140)$ & $1.02(0.125)$ \\
\hline 26 & Hemopexin* & -21.0 & $26.71(4.866)$ & $22.07(3.731)$ \\
\hline 27 & Inter-alpha (globulin) inhibitor $\mathrm{H} 2 *$ & -24.7 & $1.06(0.228)$ & $0.85(0.126)$ \\
\hline 31 & Kininogen 1 isoform $1^{*}$ & -21.0 & $5.32(0.597)$ & $4.40(0.412)$ \\
\hline 33 & LBP precursor* & 132.3 & $0.62(0.160)$ & $1.45(0.258)$ \\
\hline 36 & Serum amyloid $\mathrm{P}$ component $* \dagger$ & 71.4 & $5.86(1.801)$ & $10.04(2.117)$ \\
\hline 37 & Serum paraoxonase* & 65.1 & $3.15(0.911)$ & $5.20(1.297)$ \\
\hline 38 & $\mathrm{SHBG}^{* \dagger}$ & -57.2 & $1.26(0.374)$ & $0.80(0.247)$ \\
\hline 40 & $\mathrm{TN}^{*}$ & -34.0 & $1.21(0.184)$ & $0.90(0.129)$ \\
\hline 43 & Vitronectin* & 79.1 & $2.92(0.396)$ & $5.23(0.743)$ \\
\hline 44 & Zinc-alpha-2-glycoprotein* & 38.9 & $2.72(1.332)$ & $3.78(1.066)$ \\
\hline 4 & Alpha-2-antiplasmin & -17.1 & $2.12(0.400)$ & $1.81(0.210)$ \\
\hline 9 & Apolipoprotein A-IV & -27.2 & $9.75(3.238)$ & $7.66(2.503)$ \\
\hline 10 & Apolipoprotein E & 28.4 & $9.78(2.045)$ & $12.55(2.439)$ \\
\hline 11 & Apolipoprotein $\mathrm{J}$ (clusterin) & -24.1 & $25.93(3.564)$ & $20.89(4.544)$ \\
\hline 12 & Apolipoprotein-H (beta-2-glycoprotein-I) $\dagger$ & 8.3 & $8.84(1.344)$ & $9.57(0.852)$ \\
\hline 13 & Ceruloplasmin & -7.1 & $13.45(2.254)$ & $12.56(2.281)$ \\
\hline 25 & Gelsolin & -29.0 & $5.46(1.386)$ & $4.23(0.784)$ \\
\hline
\end{tabular}

All proteins quantified by 2D-DIGE and undergoing significant changes are listed. Values at each time point are means (SD) of the normalized volumes for proteins determined to be significant $(p<0.05)$ by repeated measures analysis of natural logarithms for each group $(n=10 /$ group). For proteins with multiple isoforms, the normalized volumes of all isoforms were added together. The percent change between time points is shown.

* Proteins that remain significantly different after the Bonferroni adjustment $(p<0.001)$ are listed in the upper portion of the table.

$\dagger$ Proteins also quantified by MAP. A complete listing of all of the proteins identified by 2D-DIGE can be found in Table S3 (http://links.lww.com/PDR/A59). CFI, complement factor I; SHBG, sex hormone-binding globulin; TN, tetranectin.

current study (Fig. 2; 800-2300\%). However, recently, the value and specificity of some of these has been questioned $(16,17)$. It is conceivable that there may be other more specific biomarkers or combinations of biomarkers, which may be more useful as predictors and monitors of SIRS. Moreover, these could be useful in terms of dividing patients with SIRS into subgroups. The analysis of a data pattern instead of several individual parameters has been shown to be advantageous for individualized predictions on postoperative recovery in cardiac surgery (18). The use of multiple parameters to assess statistical significance by data pattern analysis has also been helpful in a human model for individual risk assessment (19). Studies have successfully used multivariate logistic regression to combine data from sets of individual biomarkers to form a single-value composite index (20), along with algorithms and decision tree models (21) to accurately diagnose disease. It is also important to note that the limited size of this pilot study may have prevented some changes from reaching statistical significance, but it would be premature to eliminate these proteins from CPB studies at this time.

The dual-platform proteomics approach chosen here, which coupled 2D-DIGE and MALDI-ToF/ToF with multianalyte immunoassays, allowed us to identify and/or quantify a combined total of 129 different proteins between the two platforms: 44 by 2D-DIGE and 90 by MAPs, with five proteins being identified by both (Tables 2 and 3) and only required the use of $150 \mu \mathrm{L}$ of plasma. This total excludes the 14 most abundant plasma proteins, which we immunodepleted from our samples before 2D-DIGE. Note that the dual approach permits quantification of known (but very rare) protein analyte species using the MAP platform, simultaneously illuminating novel (but more abundant) proteins using the 2D-DIGE assay. It is likely that future 2D-DIGE studies will expand our list of identified proteins. Some of the proteins identified in this study, taken individually or together, may serve as more reliable potential biomarkers for predicting and assessing SIRS and other CPB-related complications. They could also provide additional insight into the mechanisms responsible for some of these complications. We eventually plan to incorporate these biomarkers into state-of-the-art microfluidic devices that can be used for real time measurement of the protein biomarkers of systemic inflammation (22). This would permit study of the time course of systemic inflammation, thereby enabling the development of treatment modalities to reduce or eliminate systemic inflammation and/or minimize its sequelae, thereby reducing the risks of CPB.

To enhance our understanding of the potential impact of the proteomic changes we observed with $\mathrm{CPB}$, we focused on the 70 proteins that exhibited significant changes in expression using the PANTHER gene ontology database. Ontological analysis indicated altered expression of proteins from three major categories for molecular function (SIGN, SRM, and DIP) included 65\% (46 of 71) of the significantly altered proteins and three major categories for biologic processes (ST, PMM, and ID) included 79\% (56 of 71; Fig. 3). It is interesting to note that many of the proteins falling into these highly represented categories were also the proteins that showed the greatest changes in levels of expression. 
Table 3. MAP proteins with significant changes

\begin{tabular}{|c|c|c|c|}
\hline Protein ID & Percent change & Baseline & 24 hr Post-CPB \\
\hline Adiponectin $(\mu \mathrm{g} / \mathrm{mL})^{*}$ & -43.5 & $10.41(5.149)$ & $7.25(2.349)$ \\
\hline Alpha-1 antitrypsin $(\mathrm{mg} / \mathrm{mL})^{*}$ & 49.3 & $1.66(0.497)$ & $2.49(0.490)$ \\
\hline Apolipoprotein-H (beta-2-glycoprotein-I) $(\mu \mathrm{g} / \mathrm{mL})^{* \dagger}$ & 27.0 & $112.23(22.07)$ & $142.51(33.45)$ \\
\hline Calcitonin $(\mathrm{pg} / \mathrm{mL})^{*}$ & 2865.6 & $5.82(4.071)$ & $172.66(354.2)$ \\
\hline CD40 ligand $(\mathrm{ng} / \mathrm{mL})^{*}$ & -69.6 & $0.06(0.012)$ & $0.03(0.011)$ \\
\hline Creatine kinase-MB $(\mathrm{ng} / \mathrm{mL}) *$ & 735.5 & $0.75(0.259)$ & $6.27(3.699)$ \\
\hline $\mathrm{CRP}(\mu \mathrm{g} / \mathrm{mL})^{*}$ & 800.3 & $2.30(6.017)$ & $20.74(9.514)$ \\
\hline EN-RAGE (S100 calcium binding protein A12) $(\mathrm{ng} / \mathrm{mL}) *$ & 655.9 & $2.71(3.024)$ & $20.52(12.46)$ \\
\hline Ferritin $(\mathrm{ng} / \mathrm{mL}) *$ & 408.8 & $26.51(22.55)$ & $134.87(81.21)$ \\
\hline $\mathrm{G}-\mathrm{CSF}(\mathrm{pg} / \mathrm{mL})^{*}$ & 442.4 & $6.71(14.41)$ & $36.41(39.70)$ \\
\hline IL-16 (lymphocyte chemoattractant factor) $(\mathrm{pg} / \mathrm{mL})^{*}$ & 67.3 & $491.80(262.5)$ & $822.70(297.6)$ \\
\hline Insulin $(\mu \mathrm{IU} / \mathrm{mL})^{*}$ & 689.8 & $0.40(0.343)$ & $3.17(1.965)$ \\
\hline MDC (CCL22) (pg/mL)* & -81.2 & $687.20(189.4)$ & $379.20(168.0)$ \\
\hline MMP-9 (matrix metalloproteinase 9) (gelatinase B) $(\mathrm{ng} / \mathrm{mL}) *$ & 240.3 & $158.84(160.9)$ & $540.50(275.3)$ \\
\hline Myeloperoxidase $(\mathrm{ng} / \mathrm{mL})^{*}$ & 87.0 & $126.22(80.64)$ & $236.00(53.62)$ \\
\hline Serum amyloid P component $(\mu \mathrm{g} / \mathrm{mL})^{* \dagger}$ & 96.2 & $5.67(3.696)$ & $11.13(3.937)$ \\
\hline SHBG $(\mathrm{nmol} / \mathrm{mL}) * \dagger$ & -37.1 & $72.72(19.55)$ & $53.04(14.21)$ \\
\hline TIMP-1 (ng/mL)* & 122.3 & $63.30(13.32)$ & $140.72(26.55)$ \\
\hline TNF RII (TNF receptor superfamily member 14$)(\mathrm{ng} / \mathrm{mL}) *$ & 30.0 & $3.51(1.906)$ & $4.56(1.680)$ \\
\hline Thyroid stimulating hormone (alpha; beta)* $(\mu \mathrm{IU} / \mathrm{mL})$ & -418.5 & $6.70(2.892)$ & $1.29(1.574)$ \\
\hline von Willebrand factor $(\mu \mathrm{g} / \mathrm{mL}) *$ & 100.7 & $17.69(8.133)$ & $35.50(10.64)$ \\
\hline Alpha-2 macroglobulin (mg/mL) & -10.7 & $0.79(0.074)$ & $0.72(0.040)$ \\
\hline Brain-derived neurotrophic factor $(\mathrm{ng} / \mathrm{mL})$ & -628.3 & $4.74(4.052)$ & $0.65(0.562)$ \\
\hline ENA-78 (ng/mL) & -430.5 & $1.79(1.016)$ & $0.34(0.364)$ \\
\hline Eotaxin (CCL11) (pg/mL) & -83.2 & $243.30(69.30)$ & $132.78(70.03)$ \\
\hline Fatty acid binding protein $(\mathrm{ng} / \mathrm{mL})$ & 273.0 & $2.14(2.576)$ & $7.99(7.807)$ \\
\hline Factor VII (coagulation factor VII) (ng/mL) & -26.2 & $370.64(140.3)$ & $293.60(112.2)$ \\
\hline Fibrinogen (alpha chain, beta chain, gamma chain $\dagger)(\mathrm{mg} / \mathrm{mL})$ & 21.6 & $2.37(0.858)$ & $2.89(0.538)$ \\
\hline Haptoglobin $(\mathrm{mg} / \mathrm{mL})$ & -257.3 & $0.54(0.550)$ & $0.15(0.200)$ \\
\hline IFN-gamma $(\mathrm{pg} / \mathrm{mL})$ & -584.0 & $19.12(16.17)$ & $2.80(4.144)$ \\
\hline $\operatorname{IgE}(\mathrm{ng} / \mathrm{mL})$ & 148.2 & $6.62(5.835)$ & $16.43(16.78)$ \\
\hline $\operatorname{IgM}(\mathrm{mg} / \mathrm{mL})$ & 32.3 & $0.36(0.191)$ & $0.48(0.115)$ \\
\hline IL-2 (pg/mL) & -67.0 & $30.17(12.82)$ & $18.07(5.477)$ \\
\hline IL-5 (CSF, eosinophil) $(\mathrm{pg} / \mathrm{mL})$ & -56.3 & $8.93(1.924)$ & $5.71(2.604)$ \\
\hline IL-6 (interferon, beta 2) (pg/mL) & 1075.9 & $2.50(4.769)$ & $29.35(24.89)$ \\
\hline $\mathrm{IL}-8(\mathrm{pg} / \mathrm{mL})$ & 61.0 & $30.18(6.667)$ & $48.60(13.69)$ \\
\hline $\mathrm{IL}-13(\mathrm{pg} / \mathrm{mL})$ & -20.1 & $84.31(18.47)$ & $70.21(12.02)$ \\
\hline IL-15 (ng/mL) & -41.0 & $0.99(0.628)$ & $0.70(0.482)$ \\
\hline Leptin $(\mathrm{ng} / \mathrm{mL})$ & 178.7 & $1.87(2.707)$ & $5.22(6.522)$ \\
\hline Lipoprotein (a) $(\mu \mathrm{g} / \mathrm{mL})$ & 147.0 & $17.00(12.88)$ & $41.97(36.89)$ \\
\hline MCP-1 (CCL2) (pg/mL) & -63.1 & $212.40(122.9)$ & $130.24(44.36)$ \\
\hline MIP-1beta (CCL4) (pg/mL) & -40.5 & $216.20(63.79)$ & $153.90(50.44)$ \\
\hline MMP-2 (gelatinase A) $(\mu \mathrm{g} / \mathrm{mL})$ & -42.5 & $3.31(0.962)$ & $2.32(0.759)$ \\
\hline Prostate specific antigen, free (Kallikrein-related peptidase 3) $(\mathrm{ng} / \mathrm{mL})$ & 50.9 & $0.04(0.021)$ & $0.06(0.017)$ \\
\hline RANTES (CCL5) (ng/mL) & -527.5 & $21.64(16.59)$ & $3.45(3.475)$ \\
\hline Stem cell factor (KIT ligand) $(\mathrm{pg} / \mathrm{mL})$ & -38.5 & $392.00(116.9)$ & $283.10(85.03)$ \\
\hline TNF-alpha $(\mathrm{pg} / \mathrm{mL})$ & -55.5 & $8.92(4.891)$ & $5.74(1.933)$ \\
\hline Thrombopoietin (ng/mL) & -75.9 & $3.31(0.984)$ & $1.88(0.909)$ \\
\hline VEGF $(\mathrm{pg} / \mathrm{mL})$ & 23.4 & $769.10(218.5)$ & $948.90(173.3)$ \\
\hline
\end{tabular}

All proteins quantified by MAP and undergoing significant changes are listed. Values are means (SD) of the concentrations for proteins determined to be significant $(p<0.05)$ by repeated measures analysis of natural logarithms for each group $(n=10 /$ group $)$.

* Proteins that remain significantly different after the Bonferroni adjustment $(p<0.00056)$ are listed in the upper portion of the table.

$\dagger$ Proteins were also quantified by 2D-DIGE. A complete listing of all of the proteins identified by MAP can be found in Table S4 (http://links.lww.com/PDR/A59).

G-CSF, colony stimulating factor (granulocyte); MDC, macrophage-derived chemokine; SHBG, sex hormone-binding globulin; TIMP, tissue inhibitor of metalloproteinases; ENA-78, epithelial-derived neutrophil activating protein 78; IFN, interferon; Ig, immunoglobulin; MCP, monocyte chemoattractant protein; MIP, macrophage inflammatory protein; MMP, matrix metalloproteinase; TNF, tumor necrosis factor; VEGF, vascular endothelial growth factor A.

Further analysis with Ingenuity Pathways indicated that many of the protein changes after CPB are related to the acute phase response signaling pathway ( $p<6.755 \mathrm{E}-27$; Fig. 4). This included both positive and negative acute phase elements. Given the known association of CPB with inflammation and SIRS, this was expected. IL-6, which increases by more than 10-fold, is at the proximal end of the cascade and apparently affects the regulation of a number of the proteins identified in this study through the JAK2/STAT3 pathway, including CRP and lipopolysaccharide binding protein (LBP).

A number of other canonical pathways were also implicated by the Ingenuity program on the basis of identified proteins. Among these were the coagulation system, the complement system, and cytokine-mediated signaling and glucocorticoid 


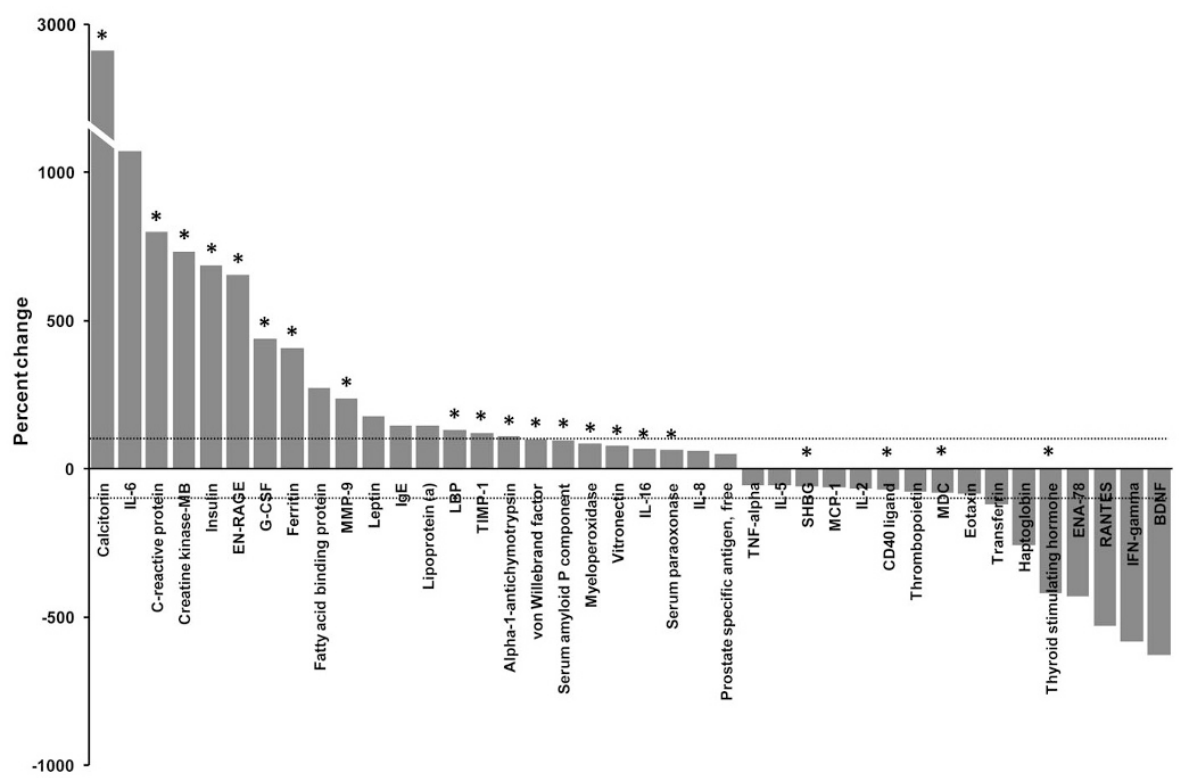

Figure 2. Histogram of significant proteins with greater than $50 \%$ change in expression. All proteins changed significantly and underwent at least a $50 \%$ change. Proteins that remain significantly different after the Bonferroni adjustment are indicated by “*."
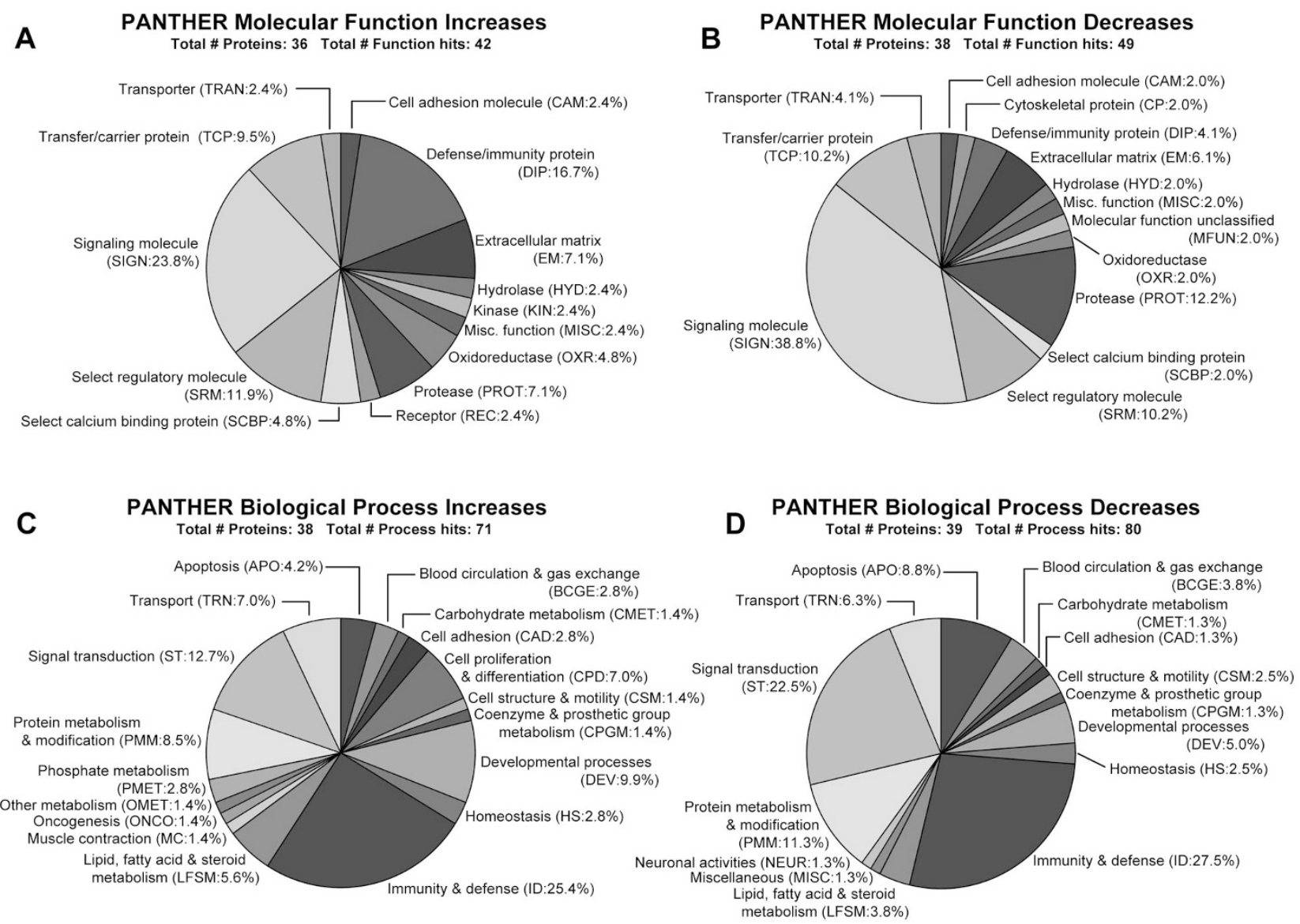

Figure 3. Pie charts of PANTHER molecular function and biologic process. The molecular functions $(A, B)$ and biologic processes $(C, D)$ assigned to the combined list of significant proteins identified by 2D-DIGE and MAP are shown, along with the percentage that each group constitutes. Only the proteins determined to be significant by repeated measurements analysis are included and are separated by increases (baseline to $24 \mathrm{~h}$ post-CPB) $(A, C)$ and decreases $(B, D)$. A complete list of the proteins with their functions can be found in Tables S3 and S4 (http://links.lww.com/PDR/A59).

receptor signaling, although there were fewer significant changes in protein expression in the proteins associated with these pathways.

Study limitations. Although all of these 10 patients fit our inclusion criteria in terms of risk stratification, body weight, and age, the duration of CPB and cross-clamp varied patient to patient. This is the limitation of our study. Another limitation of this study is that we compared only two samples (baseline versus $24 \mathrm{~h}$ post- $\mathrm{CPB}$ ); therefore, we may miss the early peak of several proteins. Because of the limitation of blood samples taken from 


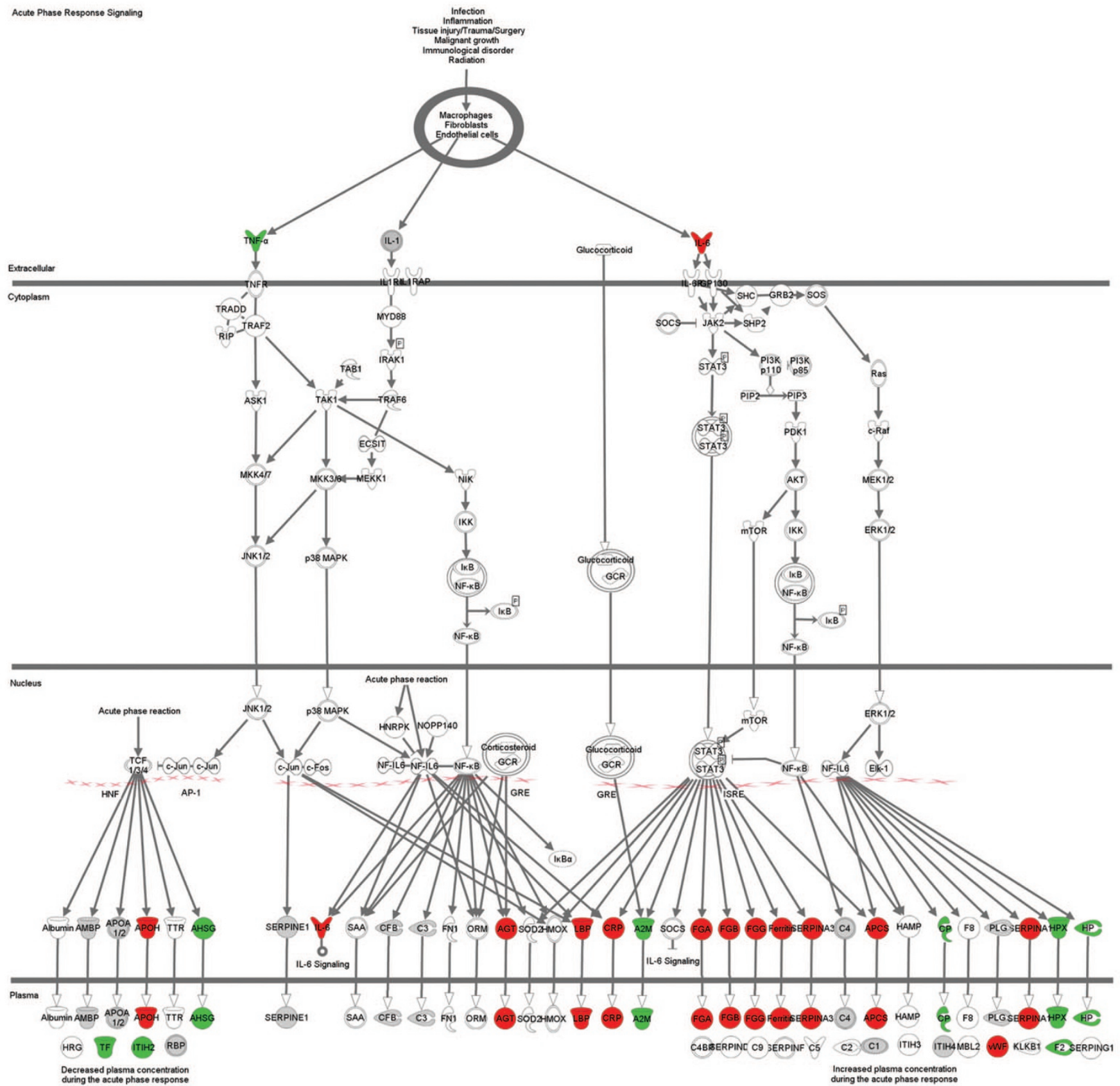

Figure 4. Acute phase signaling pathway. Ingenuity pathways analysis of a combined list of all 129 proteins identified by 2D-DIGE and MAP. The canonical "acute phase response signaling" pathway was determined to be the most highly regulated $(p<6.75 \mathrm{E}-27)$ pathway by this set of proteins. Proteins with significant increases in expression are shown in red, proteins with significant decreases are shown in green, and proteins that were identified but did not change significantly are shaded in gray.

pediatric patients, in particular from neonates and infants, we were able to take only a limited number of samples. Several previous studies (including ours) have showed significant changes in levels of biomarkers during $\mathrm{CPB}$ and at 1, 3, 6, 12, and $18 \mathrm{~h}$ post-CPB. On the basis of our past experience, usually most of the "classical" biomarkers return to normal levels after $24 \mathrm{~h}$ post-CPB. This was one of the reasons to collect the last sample at $24 \mathrm{~h}$ post-CPB. However, we have discovered that 70 proteins remained significantly changed after $24 \mathrm{~h}$ post-CPB even though the sample size was small. In addition, this study is a pilot study and will not have statistical power to correlate the levels of biomarkers and tissue damage. Rather, this is a study using a novel approach that combines two discovery proteomics techniques to identify a pattern of potential biomarkers using only $150 \mu \mathrm{L}$ of plasma.

\section{CONCLUSIONS}

This study uses a novel approach that combines two powerful proteomics techniques to identify patterns of potential biomarkers that change after $\mathrm{CPB}$. The identification and quantification of these biomarkers using only $150 \mu \mathrm{L}$ of 
plasma may provide additional insight into the mechanisms responsible for CPB-related complications, particularly systemic inflammation, and enable preventative measures or treatments to be used during and after CPB procedures to help reduce the systemic effects of $\mathrm{CPB}$ and improve the outcomes of pediatric $\mathrm{CPB}$ patients.

Acknowledgments. We thank research nurses (Sarah Sturgis, RN, MS, Jennifer Stokes, RN, Heidi Watts, RN, Jessica Beiler, MPH, and Amyee McMonagle, RN) from the Pediatric Clinical Research Office of the Department of Pediatrics for the collection of blood samples.

\section{REFERENCES}

1. Day JR, Taylor KM 2005 The systemic inflammatory response syndrome and cardiopulmonary bypass. Int J Surg 3:129-140

2. Lull ME, Freeman WM, Myers JL, Midgley F, Kimatian SJ, Ündar A, Vrana KA 2006 Plasma proteomics: a noninvasive window on pathology and pediatric cardiac surgery. ASAIO J 52:562-566

3. Lull ME, Carkaci-Salli N, Freeman WM, Myers JL, Midgley FM, Thomas NJ, Kimatian SJ, Vrana KE, Ündar A 2008 Plasma biomarkers in pediatric patients undergoing cardiopulmonary bypass. Pediatr Res 63:638-644

4. Miller A, Lu CK, Wang S, Umstead TM, Freeman WM, Vrana K, Yang S, Myers JL, Phelps DS, Zahn JD, Undar A 2009 Pediatric cardiopulmonary bypass circuits: a review of studies conducted at the Penn State pediatric cardiac research laboratories. J Extra Corpor Technol 41:P50-P58

5. Rogerson A, Guan Y, Kimatian SJ, Kunselman A, Clark JB, Myers JL, Ündar A 2010 Transcranial Doppler ultrasonography: a reliable method of monitoring pulsatile flow during cardiopulmonary bypass in infants and young children. J Thorac Cardiovasc Surg 139:e80-e82

6. Alban A, David SO, Bjorkesten L, Andersson C, Sloge E, Lewis S, Currie I 2003 A novel experimental design for comparative two-dimensional gel analysis: twodimensional difference gel electrophoresis incorporating a pooled internal standard. Proteomics 3:36-44

7. Umstead TM, Freeman WM, Chinchilli VM, Phelps DS 2009 Age-related changes in the expression and oxidation of bronchoalveolar lavage proteins in the rat. Am J Physiol Lung Cell Mol Physiol 296:L14-L29
8. Jenkins KJ 2004 Risk adjustment for congenital heart surgery: the RACHS-1 method. Semin Thorac Cardiovasc Surg Pediatr Card Surg Annu 7:180-184

9. Gibson F, Anderson L, Babnigg G, Baker M, Berth M, Binz PA, Borthwick A, Cash P, Day BW, Friedman DB, Garland D, Gutstein HB, Hoogland C, Jones NA, Khan A, Klose J, Lamond AI, Lemkin PF, Lilley KS, Minden J, Morris NJ, Paton NW, Pisano MR, Prime JE, Rabilloud T, Stead DA, Taylor CF, Voshol H, Wipat A, Jones RA 2008 Guidelines for reporting the use of gel electrophoresis in proteomics. Nat Biotechnol 26:863-864

10. Mi H, Lazareva-Ulitsky B, Loo R, Kejariwal A, Vandergriff J, Rabkin S, Guo N, Muruganujan A, Doremieux O, Campbell MJ, Kitano H, Thomas PD 2005 The PANTHER database of protein families, subfamilies, functions and pathways. Nucleic Acids Res 33:D284-D288

11. Robertson CM, Coopersmith CM 2006 The systemic inflammatory response syndrome. Microbes Infect 8:1382-1389

12. Matsuda N, Hattori Y 2006 Systemic inflammatory response syndrome (SIRS): molecular pathophysiology and gene therapy. J Pharmacol Sci 101:189-198

13. Mokart D, Merlin M, Sannini A, Brun JP, Delpero JR, Houvenaeghel G, Moutardier V, Blache JL 2005 Procalcitonin, interleukin 6 and systemic inflammatory response syndrome (SIRS): early markers of postoperative sepsis after major surgery. $\mathrm{Br} \mathrm{J}$ Anaesth 94:767-773

14. Rey C, Los AM, Concha A, Medina A, Prieto S, Martinez P, Prieto B 2007 Procalcitonin and $\mathrm{C}$-reactive protein as markers of systemic inflammatory response syndrome severity in critically ill children. Intensive Care Med 33:477-484

15. Simon L, Saint-Louis P, Amre DK, Lacroix J, Gauvin F 2008 Procalcitonin and C-reactive protein as markers of bacterial infection in critically ill children at onset of systemic inflammatory response syndrome. Pediatr Crit Care Med 9:407-413

16. Tang BM, Eslick GD, Craig JC, McLean AS 2007 Accuracy of procalcitonin for sepsis diagnosis in critically ill patients: systematic review and meta-analysis. Lancet Infect Dis 7:210-217

17. Arkader R, Troster EJ, Lopes MR, Junior RR, Carcillo JA, Leone C, Okay TS 2006 Procalcitonin does discriminate between sepsis and systemic inflammatory response syndrome. Arch Dis Child 91:117-120

18. Rothenburger M, Tjan TD, Schneider M, Berendes E, Schmid C, Wilhelm MJ, Bocker D, Scheld HH, Soeparwata R 2003 The impact of the pro- and antiinflammatory immune response on ventilation time after cardiac surgery. Cytometry B Clin Cytom 53:70-74

19. Valet G 2002 Predictive medicine by cytomics: potential and challenges. J Biol Regul Homeost Agents 16:164-167

20. Li J, Zhang Z, Rosenzweig J, Wang YY, Chan DW 2002 Proteomics and bioinformatics approaches for identification of serum biomarkers to detect breast cancer. Clin Chem 48:1296-1304

21. Petricoin EF, Ardekani AM, Hitt BA, Levine PJ, Fusaro VA, Steinberg SM, Mills GB, Simone C, Fishman DA, Kohn EC, Liotta LA 2002 Use of proteomic patterns in serum to identify ovarian cancer. Lancet 359:572-577

22. Yang S, Ündar A, Zahn JD 2007 Continuous cytometric bead processing within a microfluidic device for bead based sensing platforms. Lab Chip 7:588-595 